\title{
EXPERIÊNCIAS FORMATIVAS EM MÚSICA NA CONSTRUÇÃO DOS PROJETOS DE VIDA DOS JOVENS: UM ESTUDO A PARTIR DE ENTREVISTAS NARRATIVAS
}

\section{ANDREA MATIAS QUEIROZ}

Universidade de Brasília

Este trabalho apresenta o recorte de uma pesquisa de mestrado que teve como objetivo compreender como os jovens da Orquestra de Cordas do Projeto Música para Crianças - OMPC continuam estudando música, ao longo de suas vidas. O referencial teórico utilizado foi desenvolvido a partir dos conceitos que tratam da juventude, com base em autores como Groppo (2000), León (2005), Abramo, (2005), bem como o conceito de experiência formativa e a busca de si, no processo de formação e vida, na perspectiva abordada por Christine Josso $(2004 ; 2010)$. A metodologia utilizada consiste na abordagem autobiográfica, na qual a subjetividade dos indivíduos se torna ponto fundamental para este estudo (Delory-Momberger, 2012). A técnica de pesquisa é a Entrevista Narrativa, baseada nos pressupostos de Schutze (2010). Olhar as experiências formativas em música desses jovens poderá nos indicar caminhos para discutir as dimensões envolvidas na continuidade desses jovens, estudando música ao longo da vida.

Palavras-chave: Jovens de uma orquestra. Experiências formativas em música. Pesquisa autobiográfica.

\section{ABSTRACT FORMATIVE EXPERIENCES IN MUSIC IN THE CONSTRUCTION OF LIFE PROJECTS OF YOUNG PEOPLE: A STUDY FROM NARRATIVE \\ INTERVIEWS}

This paper presents the cutting of a master's research aimed to understand how the youth of the Orchestra of the Music Project Tethers for Children continue studying music throughout their lives. The theoretical framework was developed from the concepts that deal with youth, based on authors like Groppo (2000), Leon (2005), Abramo (2005) and the concept of formative experience and the search for you in the process training and life in perspective addressed by Christine 
Josso $(2004 ; 2010)$. The methodology used is the autobiographical approach in which the subjectivity of individuals becomes a key issue for this study (Delory-Momberger, 2012). The research technique it is the interview Narrative based on assumptions Schutze (2010). Look at the formative experiences in music these young people indicates the paths to discuss dimensions involved in the continuity of these young people studying music.

Keywords: Youth orchestra. Formative experiences in music. Autobiographical research.

\section{RESUMEN EXPERIENCIAS FORMATIVAS EN MÚSICA EN LA CONSTRUCCIÓN DE PROYECTOS DE VIDA DE JÓVENES: UN ESTUDIO A PARTIR DE ENTREVISTAS NARRATIVAS}

Este trabajo presenta el recorte de una investigación que tuvo como objetivo comprender cómo los jóvenes de la Orquesta de Cuerdas del Proyecto Música para Niños continúan estudiando música a lo largo de sus vidas. El referencial teórico utilizado fue desarrollado a partir de los conceptos que tratan de la juventud, con base en autores como Groppo (2000), León (2005), Abramo, (1994), así como el concepto de experiencia formativa y la búsqueda de sí en el proceso de formación y de la vida en la perspectiva abordada por Christine Josso $(2004 ; 2010)$. La metodología utilizada es el enfoque autobiográfico en el que la subjetividad de los individuos se convierte en un tema clave para este estudio (Delory-Momberger, 2012). La técnica de investigación es la Entrevista Narrativa basada en los supuestos de Schutze (2010). Observar las experiencias formativas en música de los jóvenes podrá indicarnos caminos para discutir dimensiones presentes en la continuidad de esos jóvenes estudiando música a lo largo de la vida.

Palabras clave: Jóvenes de una orquesta. Experiencias formativas en música. Investigación autobiográfica.

\section{Continuidade de jovens estudando música: tema e interesses}

A decisão de realizar uma pesquisa relacionada com a continuidade de jovens estudando música deu-se por conta de minhas experiências, pessoal e profissional, ao longo da minha trajetória na música, lecionando para crianças, adolescentes, jovens e adultos, em projetos, escolas especializadas e aulas particulares.

Ao longo dessas experiências, presenciei o desinteresse e a desistência dos alunos, mas, em contrapartida, também pude ver exemplos 
de superação e persistência, em suas trajetórias na música. Nos contextos em que atuei, a questão do desinteresse sempre me inquietava, pois eu me perguntava quais razões levavam esses alunos a parar de estudar música, interessando-me, principalmente, pelos motivos que tinham os demais alunos para continuar, persistir nos seus estudos e permanecer fazendo música.

A partir disso, a primeira grande pergunta que me fiz foi: "quais as razões que fazem os alunos dar continuidade aos seus estudos de música?" Esse questionamento, apesar de muito amplo, me inquietou durante muito tempo e ainda me inquieta, de certa forma. Com isso, passei, então, a observar que essa escolha dos sujeitos por continuar estudando música era algo mais complexo. No meu entendimento, isso parecia estar relacionado tanto com as singularidades do indivíduo, como também poderia ter relação com as experiências vivenciadas nos contextos em que estão inseridos. Isso me leva a pensar que a trajetória musical de um indivíduo, ou seja, a sua continuidade nos estudos em música está relacionada a diversos aspectos, tais como pessoas, ambientes, suas decisões e a persistência no fazer musical.

Partindo de leituras e experiências que englobam a minha vivência como professora, entendo que a opção do jovem por continuar estudando música é um processo multifacetado, resultante das interações do indivíduo com os ambientes nos quais está inserido, suas relações com a música e com pessoas e suas experiências, pois, como aponta Silva (2008, p. 39), as escolhas musicais dos jovens são parte de um fenômeno complexo e envolvem, além do aspecto "estético ou valorativo musical", a construção da identidade que requer, muitas vezes, movimentos de reflexão que lhes permitam mudar, repensar e trocar suas escolhas.
Uma vez que os sujeitos dessa pesquisa são os jovens da Orquestra de Cordas do Projeto Música para Crianças da Universidade de Brasília, que denomino, no decorrer do artigo, de OMPC, penso que a compreensão dos contextos dos mundos vividos pelo sujeito, tanto nos projetos de si como nos projetos coletivos, talvez traga, para a área de Educação Musical, uma concepção mais abrangente a respeito dos inúmeros aspectos que contribuem para que os jovens permaneçam estudando música nos contextos em que estão inseridos.

Em relação aos cuidados éticos da pesquisa, após dar os esclarecimentos e as informações necessárias, foi entregue um termo de autorização para cada um dos participantes. Além disso, antes de iniciar a gravação das entrevistas, indaguei os entrevistados sobre a opção de utilizar ou não o seu verdadeiro nome na pesquisa. Apenas uma das entrevistadas pediu um tempo para pensar a respeito, mas, posteriormente, comunicou-me que eu poderia utilizar seu próprio nome. Deste modo, todos eles optaram pela utilização do próprio nome no trabalho final.

Assim sendo, o foco do meu interesse foi compreender como os jovens da OMPC continuam estudando música, ao longo de suas vidas, a partir das narrativas, dos episódios e acontecimentos que marcaram sua experiência formativa. O que eles contam, o que legitimam como significativo para essa escolha aparecerá nos episódios de suas histórias de vida com a música.

\section{A experiência como formação}

Para compreender os caminhos construídos pelos jovens músicos da OMPC, parto de uma perspectiva autobiográfica, abordando o conceito de experiência como formação, na perspectiva teórica de Josso (2004), para quem a experiência é a vivência carregada de significado, isto é, a vivência da qual nos tornamos 
conscientes de nós mesmos, e isso tem a ver com o questionamento que fazemos sobre o que vivemos, sobre como estamos nos tornando indivíduos e, principalmente, sobre o conhecimento de nós mesmos, das relações que são estabelecidas no nosso processo formativo e nas aprendizagens construídas ao longo da vida.

Para esta reflexão, dialogo com as questões apresentadas por Josso (2010), no que se refere às experiências formadoras que, pela força de sua significação, foram fundadoras e desencadearam os rumos de sua vida. Partindo de uma visão, ao mesmo tempo, retrospectiva e prospectiva, esta autora extraiu de seu percurso vivências que se transformaram em experiências e contribuíram para a sua (trans)formação.

Essa busca de si é abordada pela autora através da metáfora do "caminhar para si", como um meio de ter o controle da própria vida, de tornar-se sujeito de si, adotando uma postura ativa frente a suas experiências e a sua vida.

A metáfora sugere a atividade de um sujeito que inicia uma viagem e, no decorrer do caminho, a partir dos encontros e acontecimentos, ele se localiza no espaço-tempo do aqui e agora e procura compreender o que o orientou durante essa caminhada, fazendo o registro das suas bagagens e recordando os seus sonhos e desilusões, procurando voltar para si a partir dos caminhos percorridos. Nas palavras de Josso (2010, p. 84), “ir ao encontro de si visa à descoberta e à compreensão de que viagem e viajante são apenas um". A partir desse encontro de si, o sujeito reflete sobre suas vivências e, consequentemente, transforma-se em alguém capaz de coordenar a sua própria vida. A tomada de consciência das experiências revela aspectos do sujeito que emergem como um referencial experiencial que pode ser considerado como um pressuposto constitutivo da maneira de ser do sujeito, ao alicerçar suas ideias e pensamentos, e exteriorizar aspectos que manifesta em suas relações e no contexto em que se encontra.

Nessa perspectiva, em se tratando dos mundos dos jovens e seus contextos musicais, a formação é vista aqui como a relação que esses jovens estabelecem com os tempos/ espaços que vivenciam, e nos quais fazem as suas apropriações e constroem experiências musicais.

Partindo do que foi exposto acerca do processo de caminhar para si, acredito que uma forma de fazer esse percurso, ou seja, de entender as próprias decisões e tornar-se sujeito de si, seja vislumbrar ao longo da vida a imagem de um projeto futuro que transcende a ideia de uma concretização profissional e busca o entendimento, a construção e o encontro de si mesmo no mundo.

\section{Compreensões teóricas e} metodológicas da autobiografia e a entrevista narrativa

O que constitui o projeto epistemológico da pesquisa biográfica, abordagem metodológica utilizada para esta pesquisa, é a constituição individual do sujeito (DELORY-MOMBERGER, 2012).

De acordo com a autora, o objeto de estudo da pesquisa biográfica inscreve-se em uma das questões centrais da antropologia social, buscando compreender "como os indivíduos se tornam indivíduos?" (2012, p. 523). Essa temática convida outras áreas do conhecimento a desdobrar outras questões que tratam da complexidade das relações dos indivíduos e suas inscrições nos contextos históricos, sociais, culturais, linguísticos, econômicos e políticos.

Os desenvolvimentos teóricos mais recentes da pesquisa biográfica, propostos por Delory-Momberger (2008; 2012), têm evidenciado 
o carácter eminentemente transdisciplinar do trabalho que recorre ou se baseia em histórias de vida, narrativas biográficas e material autobiográfico.

Para a autora, tal proposta toma em consideração tanto as dimensões sociais, políticas, históricas, discursivas, culturais, presentes nas abordagens biográficas, como as aproximações entre diferentes correntes ou tradições da pesquisa com e sobre as histórias de vida, nas ciências sociais e humanas, nos últimos cem anos.

Assim, a abordagem biográfica é relevante para a compreensão das posições e dos papéis ocupados pelos indivíduos na estrutura social. Assim, só podemos reconstruir o mundo de nossas vidas narradas à medida que relacionamos esse mundo aos nossos construtos biográficos e os compreendemos nas relações de ressonância com a nossa própria experiência biográfica (DELORY-MOMBERGER, 2008).

Para Delory-Momberger (2008), a forma de expressão mais imediata para demonstrar a representação mental, pré-escritural de uma biografia são as narrativas. A autora esclarece que os princípios do discurso narrativo consistem em organizar a sucessão dos fatos, as sintaxes das ações e das funções, a dinâmica transformadora entre sequências de abertura e de fechamento dos acontecimentos, além de orientar quanto aos objetivos do sujeito em narrar determinados fatos. Nesse sentido, a narrativa apresenta-se como a linguagem do fato biográfico, como o discurso no qual escrevemos nossa vida.

Por meio das narrativas, podemos ter acesso à experiência do outro, porém de modo indireto, pois a pessoa traz a sua experiência da maneira como ela a percebe, ou melhor, da maneira como a interpreta. A pessoa narra suas experiências, reconstruindo eventos passados de uma maneira congruente com sua compreensão atual, ou seja, o presente é explicado tendo como referência o passado reconstruído, e ambos são usados para gerar expectativas sobre o futuro.

Assim, ao narrar a sua própria história, o indivíduo age e produz ação, e a ação que produz se exerce sobre o texto enquanto forma, mas se exerce também sobre o agir humano a que se refere o texto. Contudo, o relato não é somente o produto de um ato de contar, ele tem também o poder de produzir efeitos sobre aquilo que relata. A identificação e o tratamento cruzado desses relatos permitem tornar legiveis os princípios estruturais que organizam o percurso de autoformação de quem narra, ao mesmo tempo em que dão conta de sua singularidade.

Com base nessas concepções fundantes da pesquisa, a técnica de coleta de dados utilizada foi desenvolvida pelo sociólogo alemão Fritz Schutze, e trata-se do método de análise de dados narrativos conhecido como entrevista narrativa (SCHUTZE, 2010).

Ao idealizar essa forma de entrevista, Schutze (2010) parte do princípio de que a narração está mais propensa a reproduzir em detalhes as estruturas que orientam as ações dos indivíduos. Nesse sentido, Weller (2009) observa que, na abordagem idealizada por Schutze, a entrevista narrativa não foi criada com o intuito de reconstruir a história de vida do informante, em sua especificidade, mas de compreender os contextos em que essas biografias foram construídas.

Nesse sentido, ao contar um acontecimento, a pessoa tem compromisso com a expressão simbólica do mundo e como ele funciona. Ela se refere a um acontecimento que ocorreu no passado, mas, agora, à luz de novas vivências, de outros conhecimentos que adquiriu, de outros padrões de comportamento que socialmente são estabelecidos, enfim, ela reconta o acontecimento a partir de novas reflexões sobre a experiência passada. 
Essa compreensão da narrativa permite perceber a realidade como um processo dinâmico, criativo, em que tanto o narrador quanto a realidade renascem, tornando única cada narrativa. A vida de uma pessoa tem muitas ramificações, entrelaçamentos, expansões e uma infinidade de possibilidades a serem realizadas, que se relacionam com muitas outras experiências, permitindo que um evento seja contado e recontado de diferentes maneiras, considerando-se diferentes pontos de vista.

\section{Experiências formativas em música dos jovens da OMPC}

Ao narrarem sobre o início da trajetória musical e o processo de entrada no mundo da música, os jovens entrevistados da pesquisa revelam percursos vividos no contexto familiar, escolar e social, como lugares que contribuem e imprimem marcas significativas em todo o seu percurso musical.

Relembrar a trajetória revela, na totalidade do grupo, lembranças e aprendizagens construídas em diferentes espaços. As referências feitas às diversas pessoas do convívio, nesses contextos, que exercem influência no percurso da vida, são vinculadas à "aprendizagem experiencial" da vida de cada sujeito. Pais, professores, familiares, amigos, vizinhos e colegas são marcantes nas narrativas, por envolverem experiências formadoras e regulações necessárias ao processo educativo, ao desenvolvimento pessoal e às mudanças que ocorrem na vida dos sujeitos, configurando assim uma perspectiva formativa ao longo da vida.

Considerando que a continuidade dos jovens da OMPC na música pode se sustentar e fortalecer nas relações construídas, a partir das pessoas e das vivências musicais experienciadas, apresento a seguir os principais aspectos constituintes dessas experiências relatados pelos jovens.

\section{A influência da família}

A família exerce um papel fundamental na constituição e na formação dos indivíduos. A convivência familiar vai criando normas, crenças, valores, culturas próprias, trazidas pelo grupo de convivência, pelas instituições ou pela mídia. Isso pode direcionar os indivíduos, em suas escolhas e decisões, quanto ao que fazer na vida, desenvolvendo expectativas em relação aos outros e à imagem de si mesmos como pessoas.

De acordo com as narrativas dos jovens, a presença dos pais tem uma função importante na continuidade dos estudos em música, pois, como relatado, além dessa presença, existe um esforço por parte dos mesmos para que seus filhos continuem estudando, como fica claro no seguinte relato:

Uma coisa boa é que a minha mãe, ela sempre ia nas aulas comigo, até os 14 anos, ela sempre acompanhava muito, tipo, por mais que quando eu tava em casa eu estudava sozinho, ela ia na aula comigo, então ela sabia. (Luiz Paulo)

Ao ressaltar a presença da mãe em suas aulas, de uma forma positiva, o jovem demonstra o quanto a base familiar influenciou a sua trajetória, pois à medida que ele recebe esse apoio, a sua relação de continuidade na música se fortalece.

Para Ruth, a importância da mãe também foi fundamental ao seu processo formativo. Como mostra o relato a seguir, Ruth atribui à mãe a principal influência para ela ter iniciado a carreira musical.

$\mathrm{Na}$ verdade, quem me influenciou mesmo foi minha mãe porque ela sempre gostou de piano na infância dela. Aí a minha mãe me colocou pra ter aula, daí eu comecei a aprender teclado e flauta junto com a minha irmã. (Ruth)

De acordo com as narrativas dos jovens, a presença dos pais exerce uma função importante na continuidade dos estudos em músi- 
ca, pois, como relatado, além dessa presença, existe um esforço por parte dos mesmos para que seus filhos continuem estudando. Esse esforço é visto pelos entrevistados como algo que pode ter contribuído para a continuidade dos estudos em música. Nesse sentido, já existem estudos que abordam essa temática.

Segundo Santos (2005), a família é apontada pela literatura como um dos principais aspectos que podem tanto ajudar quanto dificultar o jovem na tomada de decisões relacionadas ao futuro profissional. A questão da atuação da família, nessas escolhas, transparece tanto no discurso dos pais como no discurso dos próprios jovens. Há sempre alguma maneira de influenciar, seja expressando abertamente a opinião ou, muitas vezes, pressionando o filho a seguir determinada profissão.

o indivíduo, ao nascer, já carrega consigo uma série de expectativas da família, que ele deverá (ou não) cumprir ao longo da vida. Os pais depositam seus sonhos nos projetos que fazem para o futuro dos filhos e estes se desenvolvem nesse contexto. Assim, o jovem se depara com a necessidade de implementar uma série de escolhas relativas ao seu futuro escolar e profissional.

O jovem tende a buscar o primeiro apoio na família, na hora de fazer essas escolhas. É na família que ele encontra o suporte para a realização do seu projeto. Conforme percebido por Santos (2005, p. 63), "a família é um entre os vários facilitadores ou dificultadores do processo de escolha, mas antes de tudo tem um papel importante na realidade do jovem e deve ser levada em consideração quando se trata de projeto de vida".

A influência da família, ou da rede de relações que se forma em cada família, está sempre presente de alguma maneira nas diferentes escolhas que fazemos na vida. Assim, a combinação das expectativas da família, da história de vida familiar, do comprometimen- to dos pais, do encorajamento e da interação presente na vida musical dos jovens tem contribuído para a continuidade dos seus estudos em música.

\section{Relação dos alunos com o professor}

Apesar de estabelecida por um programa, um conteúdo, normas internas ou até pela infraestrutura da instituição, é a interação entre o professor e o aluno que vai dirigir o processo educativo. Conforme a maneira pela qual esta interação se dá, a aprendizagem do aluno pode ser mais ou menos facilitada e orientada, em uma ou outra direção. Como toda relação, esta também é composta de dois polos - professor e aluno - e cabe a ambos determinar o clima desta relação. Nesse sentido, observamos, nas narrações dos entrevistados, a importância que cada um deles dá a essa relação:

[...] Eu acho que um professor que dá a vida pra dar aula, tem muita vontade, tem carinho, tem amor à profissão, ele consegue ter uma relação boa com o aluno, mesmo que ele cobre e puxe sempre o ritmo. (Ruth)

No caso de Ruth, ela considera essa "boa" relação entre professor e aluno como algo primordial para o seu aprendizado, e vai além disso, considerando que, no modo de ensinar do professor, deve existir "vontade", "carinho" e "amor à profissão". o que Ruth interpreta como sentimentos necessários à profissão está relacionado a uma visão mais ampla da forma de ensinar, na qual o aluno deve ser considerado como um sujeito interativo e ativo no processo de construção do conhecimento, proporcionado um clima de apoio mútuo entre professores e alunos.

O professor também tem um papel de grande relevância, uma vez que se apresenta como pessoa mais experiente e com mais conhecimento sistematizado, dando o apoio e o incen- 
tivo que o aluno necessita para a manutenção do seu aprendizado, como pode ser observado no relato de Marília:

O estímulo dos professores é sempre essencial, essencial, porque quando você tá nessas crises assim tipo "ah, eu sou muito ruim", eles "não, tô vendo seu crescimento, você melhorou nisso, nisso e naquilo, muita coisa precisa melhorar, mas já tem isso, isso e aquilo e então vamo nessa! Não desiste não", eles são maravilhosos meus professores, eu dei sempre muita sorte. (Marília)

A narrativa de Marília demonstra como o estímulo do professor é fundamental ao seu processo de continuidade na música. Durante os momentos de desânimo, esse estímulo se torna decisivo na opção de permanecer na carreira musical, pois, quando ela se sente insegura em relação ao seu aprendizado, é a fala do professor que a ajuda a continuar estudando música, e essa fala tem um significado especial, pois vem de alguém que conhece e acompanha de perto o seu percurso musical.

Partindo dos relatos dos jovens entrevistados, é possivel perceber que, durante a trajetória musical, o incentivo do professor se torna fundamental, pois ele dá um suporte técnico e afetivo ao aluno, o que o ajuda a analisar a própria trajetória através de um outro ângulo, possibilitando-lhe enxergar dificuldades e desafios como possibilidades de crescimento.

Para além da troca de conhecimentos e ensinamentos, como podemos ver nos relatos dos jovens, está presente nessa relação um aspecto emocional e afetivo, pelo qual o aluno reconhece na figura do professor alguém em quem ele pode confiar e apoiar as suas escolhas profissionais. À medida em que o jovem recebe, do professor, o incentivo para continuar suas atividades musicais, ele se sente fortalecido e capaz de seguir em frente, rumo ao seu objetivo.
Seguindo esta perspectiva, de acordo com Gómez (2000), o papel do professor é ser o facilitador, buscando a compreensão comum, no processo de construção do conhecimento compartilhado, que se dá pela interação. Esse processo deve provocar a reflexão sobre as próprias ações, suas consequências para o conhecimento e para a ação educativa. Nesse mesmo raciocínio, Loyola (2004) defende a ideia de que a relação professor/aluno é afetada pelas ideias que um tem do outro e até mesmo as representações mútuas entre os mesmos, por isso, a interação professor/aluno não pode ser reduzida ao processo cognitivo de construção de conhecimento, pois se envolve também nas dimensões afetivas e motivacionais.

Deste modo, as experiências adquiridas na relação professor/aluno exercem uma força que os move a seguir em seus estudos com a música. Essa relação pode influenciar em aspectos como ânimo e motivação para estudar, pois, a partir do incentivo do professor, o aluno responde em consonância a esse incentivo, sentindo-se apoiado e passando a acreditar em si mesmo.

\section{Momentos de desânimo}

Como em muitas trajetórias pessoais, os momentos de desânimo também estão presentes no percurso desses jovens e configuram-se em importantes fases da vida, pois é frente a esses momentos de desânimo e desestímulo que eles procuram meios de superar os obstáculos e fortalecer a sua escolha: continuar estudando música.

Os motivos para esses momentos de desânimo são variados, de acordo com a trajetória pessoal de cada um deles. No caso de Brenda, a entrada na faculdade e a percepção do nível de exigência do curso a fizeram pensar que ela não ia ser capaz de acompanhar o curso, entretanto esse fato não foi suficiente para fa- 
zê-la desistir e a vontade de não desistir a fez seguir em frente.

[...] Mas, assim, eu fiquei desanimada um tempo... Logo que eu entrei na faculdade, porque eu achava que era um ritmo e era outro e a exigência era muito maior. Aí, eu pensava que eu não ia dar conta, mas eu não ia desistir, daí eu fiquei. (Brenda)

Torna-se importante pensar nos motivos dessa vontade de não desistir, pois, quando Brenda expressa essa decisão, entende-se que isso é resultado de um processo de escolhas que ela vem fazendo, ao longo de toda a vida, o que sinaliza para o fato de que o processo de se manter em uma atividade também é permeado por rupturas e os momentos de desânimo também servem para reforçar a continuidade, à medida que levam o jovem a refletir sobre a sua trajetória, os motivos para continuar e também sobre as suas expectativas futuras.

Já no caso de Luiz Paulo, o principal momento de desânimo ocorreu ainda na infância, quando vivenciava outros conflitos pessoais que acabaram influenciando a sua vida com a música.

Acho que todo mundo já teve momento de desânimo né, a minha fase disso foi mais ou menos entre os 10, 11 anos [...] eu tava mudando de colégio também, aí queria mais sair com os amigos e tudo, eu gostava muito de esporte também, aí, muitas vezes, assim, eu fiquei... eu ficava na dúvida, sabe? Se eu queria mesmo fazer música e tudo... (Luiz Paulo)

Esses momentos vividos na transição entre a infância e a adolescência, como no caso de Luiz Paulo, são bastante comuns, pois envolvem diversas mudanças na vida do indivíduo que acarretam em dúvidas e conflitos que podem ser bastante importantes na formação desse indivíduo. Em relação aos motivos para continuar, o entrevistado relata:

Eu acho que é essa vontade de ser, de fazer uma coisa bem-feita, de querer realmente ser bom.
Tipo assim, várias vezes, quando eu me sinto um pouquinho desestimulado, aí eu penso "pô, ainda dá tempo de recuperar, de fazer o meu melhor". (Luiz Paulo)

O que direciona a continuidade do jovem Luiz Paulo é a sua vontade de se aprimorar naquilo que faz, de se perceber nos seus avanços musicais, ou seja, é partindo dessa relação entre presente, o que ele faz atualmente, e futuro, o que ele poderá fazer para melhorar, que ele encontra razões para continuar estudando música.

Nesse sentido, podemos pensar no conceito de competência advindo da teoria da motivação, que, segundo Guimarães (2001), trata-se da capacidade do ser humano estabelecer uma interação com o contexto em que vive, considerando uma tendência motivacional inata ao ser humano para atuar de forma competente no ambiente. Para essa perspectiva teórica, a competência é considerada um senso motivacional intrínseco, de forma a nortear os indivíduos em direção à forma mais eficaz possivel de interação com o meio. Assim, a necessidade de competência, identificada no relato de Luiz Paulo, reflete o desejo que ele tem de provar suas capacidades e habilidades. Deste modo, a satisfação dessa necessidade fornece uma motivação capaz de gerar esforços para a superação de desafios.

Nas narrativas dos quatro jovens, podemos observar a relação existente entre momentos de desânimo e momentos de mudança, em suas vidas, sejam elas em seus ambientes, em suas condutas referentes a determinadas fases da vida, em suas interpretações do passado ou em suas expectativas futuras.

Passar por momentos de desânimo faz parte da vida de todo ser humano. Mas, de certa forma, esses momentos ajudam a fortalecer a continuidade. Para esses jovens, continuar estudando música, ao longo da vida, é também sentir-se desanimado e aprender a superar. 
Deste modo, o processo de continuar é permeado de rupturas e essas rupturas mostram aos jovens que, em todas as trajetórias, existem dificuldades, mas sempre é possivel continuar, se existe um movimento para isso.

De acordo com Delory-Momberger (2012), as transformações que ocorrem com as pessoas durante os períodos de transição põem a prova as representações de si e as atividades que constituíram como normas pessoais de sua socialização, o que pode, muitas vezes, ocasionar períodos de desânimo e descontinuação das atividades.

Assim, a reflexão realizada sobre si, nesses períodos de questionamento, é essencial, pois é a partir disso que os jovens relacionam as avaliações que fazem de si mesmo às realidades nas quais atuam, encontrando não apenas razões para vencer os desânimos, mas principalmente a capacidade de agir em seus ambientes e se tornarem agentes da sua própria história, construindo uma visualização do seu futuro com a música. Para isso, apresento a seguir indícios da contribuição dos projetos pessoais na continuidade dos estudos em música e na construção dos projetos pessoais, ao longo de toda a trajetória musical desses jovens.

\section{A música como um projeto de vida}

Os projetos pessoais são fundamentais para a continuidade dos jovens, nos seus percursos musicais, pois a idealização de um objetivo ou sonho leva o jovem a dar segmento as suas atividades musicais e a construir seus caminhos, buscando situações e experiências que fortaleçam essa continuidade.

Ao construírem um projeto futuro, os jovens visualizam elementos como a consolidação de uma carreira, uma segurança financeira advinda da profissão ou até a realização de um sonho. Apesar de se diferenciarem de acordo com o desejo de cada entrevistado da pesqui- sa, esses elementos são norteadores de suas trajetórias, servindo como meio de incentivo à continuidade daquilo que eles escolheram e projetaram para suas vidas.

Essa persistência pode ser observada no relato de Marília acerca do seu processo de estudo, objetivando passar no vestibular em música.

[...] Eu primeiro tive que me disciplinar, estudava quatro horas por dia meu instrumento, tudo que a professora passava e tinha meus horários de relaxamento, meus horários de meditação, foi um período que eu tava trabalhando mesmo pra poder entrar aqui, trabalhando o mental, fisico, espiritual, tudo, e o instrumento principalmente. Então, quando eu passei, foi assim, foi uma vitória, falei “pronto, agora é isso, agora é mais que certeza, agora vamos fazer, vamos nessa!" (Marília)

Em sua narração, vê-se que Marília tem bastante clareza das ações que deve realizar. Marília organiza nessa narrativa uma sequência de ações, de situações de aprendizagem que a levaram ao objetivo estabelecido. Ou seja, em sua percepção, a entrevistada planejou situações que acreditava serem necessárias para a concretização de seu projeto. A partir disso, ela iniciou um processo de realização sequenciada dessas ações, preocupando-se também com a sua autoformação geral.

Assim, manter um objetivo final, no caso passar no vestibular em música, fez com que Marília buscasse uma disciplina em sua vida e percorresse um "caminho para si", que proporcionou o entrelaçamento da sua formação e autoformação, tornando-se ao mesmo tempo consciente de suas ações e autônoma em sua vida.

Ruth também possui bastante clareza do percurso que precisa caminhar para chegar ao objetivo almejado.

Então, primeiramente eu quero entrar aqui na universidade mesmo, fazer o bacharelado, depois um mestrado e, mais pra frente, quero fa- 
zer um concurso como esse da orquestra sinfônica de Brasília [...]. E se surgir alguma bolsa pra viajar pra fora, mais pra frente né... Mas eu quero ficar aqui em Brasília mesmo e ser solista também. (Ruth)

Na narrativa de Ruth, fica bastante clara a importância de manter um projeto em vista, e como ela espera construir esses caminhos para realizar o seu projeto de vida. Ruth esquematiza um caminho que acredita ser necessário percorrer para levá-la ao seu objetivo, o de ser solista de uma orquestra. Partindo desse sonho, ela delineia suas experiências de acordo com o caminho que resolveu percorrer, e a partir disso traça estratégias que a levem pouco a pouco a concretizar as ações que acredita serem necessárias para a realização do seu projeto de vida.

Ao evidenciar os projetos musicais futuros dos jovens da OMPC, podemos perceber que existe uma relação de temporalidade referente ao passado/presente/futuro. Assim, podemos perceber que, para transformar o presente, os entrevistados projetam o futuro e encontram, nessa relação de temporalidade, um meio de delinear seus caminhos, ou seja, é partindo da visualização de um objetivo ou situação futura que eles fazem as escolhas para vivenciarem o presente. Segundo Josso (2010):

O presente é articulado com o passado e com o futuro, que começa, de fato, a elaborar-se um projeto de si por um sujeito que orienta a continuação da sua história com uma consciência reforçada dos seus recursos e fragilidades, das suas valorizações e representações, das suas expectativas, dos seus desejos e projetos. (JOSSO, 2010, p. 23)

Partindo do pensamento da autora, entendo que desde o momento em que esses jovens objetivam a realização de um projeto de profissionalização, traçam estratégias para realizá-lo e buscam uma identificação no seu percurso de vida. Eles transcendem o âmbito profissional e ingressam em uma caminhada de reflexão pessoal que, consequentemente, os levará a um processo de (re)significação da sua vida e da caminhada para si mesmos.

Assim, a partir dos projetos futuros narrados pelos jovens, emerge o conhecimento de si e as dimensões formativas e autoformativas. Revelam-se, ainda, aprendizagens experienciais que potencializam formas de compreensão da continuidade dos jovens entrevistados estudando música. Além disso, tornam-se explícitos os significados e os sentidos exercidos pelos espaços em que estão inseridos, no que se refere às influências, às decisões tomadas e aos caminhos percorridos por esses jovens, ao longo de suas trajetórias musicais.

\section{Algumas considerações}

Nas narrativas dos jovens da OMPC, podemos observar a construção das suas trajetórias, bem como a sua continuidade na música sendo delineada nas experiências relatadas sobre determinados aspectos, como a influência dos pais, as relações estabelecidas com professores, os momentos de desânimo presentes na trajetória musical e os seus projetos de vida.

Dentre os aspectos citados, sobressai-se, como principal agente motivador da continuidade, o projeto futuro com a música, pois, ao se depararem com momentos de dificuldade e desestímulo, os jovens começam a enxergar e a refletir sobre as fragilidades do próprio percurso e, frente a essas fragilidades, os jovens voltam-se para si, buscando apoio nos seus sonhos. Isso, consequentemente, os leva a repensar o seu projeto de vida.

Ao iniciar os estudos em música, os jovens aproximam-se de um novo universo e, na medida em que o conhecem e estabelecem relações pessoais e afetivas, eles iniciam uma caminhada em direção ao seu projeto de vida.

Nessa perspectiva, acredito que, ao olhar para o futuro, os jovens imprescindivelmente, 
olham para si, pois, projetar um sonho e construir uma estratégia para realizá-lo, é um processo complexo, que exige uma gama de escolhas e reflexões que os leva a ressignificar suas vivências e a refletir sobre suas próprias experiências formadoras.

A reflexão e a ressignificação das experiências aos poucos os tornam pessoas capazes de tomar as próprias decisões frente aos diferentes caminhos encontrados na vida. Nessa perspectiva, continuar na trajetória musical está relacionado à construção de um projeto de vida com a música e, consequentemente, não se pode dar corpo a esse projeto sem se tornar sujeito de si mesmo, isto é, sem fazer uma caminhada para si (JOSSO, 2010).

Refletir sobre suas histórias com a música torna-se um instrumento para auxiliar os jovens a tomarem consciência das decisões que pesam sobre sua maneira de ser/estar no mundo, e, ao descobri-las, abrem-se outras possibilidades. Assim, os jovens descobrem-se fenômenos de si mesmos e passam a olhar o seu projeto futuro e a busca de si como uma construção do seu próprio ser/estar no mundo.

Foi possivel perceber, também, pelos resultados obtidos nesta pesquisa, que, para esses jovens, ter um objetivo futuro faz com que eles enfrentem as adversidades e busquem ultrapassar obstáculos encontrados no seu percurso, pois concebem algo para o futuro e traçam caminhos que acreditam ser adequados para alcançar esse objetivo. Ao construírem um projeto futuro, os jovens visualizam elementos, como a consolidação de uma carreira, uma segurança financeira advinda da profissão ou até a realização de um sonho.

Com base no que foi exposto, creio que a área de Educação Musical tem, dentre os seus

\section{Referências}

ABRAMO, H. W. Cenas juvenis. Punks e darks no espetáculo urbano. São Paulo: Página Aberta, 1994. compromissos, o papel de levar o indivíduo, na sua relação com a música, a uma busca do caminhar para si. Nessa perspectiva, que emerge a partir dos resultados da pesquisa, para ensinar e aprender música, faz-se necessário pensar uma educação ampla que promova, no processo de aprendizagem, a reflexão da própria trajetória, das vivências e experiências formadoras.

Acredito que essas aproximações epistemológicas entre as áreas de Educação Musical e Autobiografia, nos mostram mais um caminho para refletir sobre o ensino e a aprendizagem da música com foco no sujeito, visto que a autobiografia permite ir além de apenas contar a história com a música, captando o seu significado na vida dessas pessoas, em seus diferentes contextos. Contar, ouvir e compreender as histórias de vida com a música é, portanto, uma forma de tornar a experiência vivida disponível para outros, que as recontarão, criando, então, uma rede de conhecimento, o que permitirá sempre um novo contar sobre sua própria experiência a partir de outras experiências e outros contextos.

Assim, ao serem registradas, as histórias desses jovens com a música se tornam disponíveis a outros leitores, abrindo novas possibilidades de interpretação. As narrativas criam um campo para a ação coletiva, legitimando certas identidades e conduzindo os jovens a tomarem posições que estão de acordo com seus projetos pessoais. Isso também permite aos profissionais da área de Educação Musical refletirem sobre seus conhecimentos e determinadas situações e experiências que contribuem para o processo de continuidade nos estudos em música.

DELORY-MOMBERGER, Christine. A condição biográfica: ensaios sobre a narrativa de si na modernida- 
de avançada. Tradução de Carlos Galvão Braga, Maria da Conceição Passegi e Nelson Patriota. Natal: EDUFRN, 2012.

DELORY-MOMBERGER, Christine. Biografia e educação: figuras do indivíduo-projeto. Tradução de Maria da Conceição Passeggi, João Gomes da Silva Neto e Luis Passeggi. Natal: EDUFRN; São Paulo: Paulus, 2008.

GÓMEZ, A. I. P. A aprendizagem escolar: da didática operatória à reconstrução da cultura na sala de aula. In: SACRISTÁN, J. G.; PÉREZ GÓMEZ, A. I. Compreender e transformar o ensino. 4. ed. Porto Alegre: Artmed, 2000. p. 53-64.

GROPPO, Luís Antonio. Juventude: ensaios sobre sociologia e história das juventudes modernas. Rio de Janeiro: DIFEL, 2000.

GUIMARÃES, Sueli Édi Rufini. Motivação intrínseca, extrínseca e o uso de recompensas em sala de aula. In: BORUCHOVITCH, Evely; BZUNECK, José Aloyseo. (Orgs.). A motivação do aluno: contribuições da psicologia contemporânea. Petrópolis, RJ: Vozes, 2001. p. 37-57.

JOSSO, M. C. Experiências de vida e formação. Tradução de José Cláudio e Júlia Ferreira. Lisboa: Educa, 2004.

JOSSO, Marie-Christine. Caminhar para si. Tradução de Albino Pozzer. Porto Alegre: EDIPUCRS, 2010.

LEÓN, Oscar Dávila. Adolescência e juventude: das noções às abordagens. In: Maria Virgínia de Freitas
(Org.) Juventude e adolescência no Brasil: referências conceituais. São Paulo: Ação Educativa, 2005, p.9-18. Disponivel em: <http://www.acaoeducativa. org>. Acessado em 28/11/2016.

LOYOLA, Marcia Rocha. A importância da relação da afetividade entre professor/aluno para o desenvolvimento da educação infantil. 2004. 66 f. (Especialização em Psicopedagogia) - Faculdade de Educação, Universidade Candido Mendes - Projeto a Vez do Mestre, Niterói, 2004.

SANTOS, L. M. M. O papel da família e dos pares na escolha profissional. Psicologia em Estudo, v. 10, n.1, p. 57-66, 2005.

SCHUZE, F. Pesquisa bibliográfica e entrevista narrativa. In: WELLER, W.; PFAFF, N. Metodologia da pesquisa qualitativa em Educação: teoria e prática. Petrópolis, RJ: Ed. Vozes, 2010. p. 210-222.

SILVA, Helena Lopes da. Música, juventude e mídia: o que os jovens pensam e fazem com as músicas que consomem. In: SOUZA, Jusamara. (Org.). Aprender e ensinar música no cotidiano. Porto Alegre: Sulina, 2008. p. 39-57.

WELLER, Wivian. Tradições hermenêuticas e interacionistas na pesquisa qualitativa: a análise de narrativas segundo Fritz Schutze. In: REUNIÃO ANUAL DA ANPED, 32., 2009, Caxambu. Anais... Caxambu: ANPED, 2009. p. 1-16.

Recebido em: 12.05.2017

Aprovado em: 31.07.2017

Andrea Matias Queiroz é Mestre em Música pelo Programa de Pós-Graduação Música em Contexto da Universidade de Brasília. e-mail: vlnandrea@yahoo.com.br

Setor de Grandes Áreas Norte 609, UnB - Asa Norte, Brasília - DF

Telefone: (61) 982875934 